\title{
VIOLÊNCIA DOMÉSTICA E SUAS CONSEQUÊNCIAS
}

PSICOEMOCIONAIS

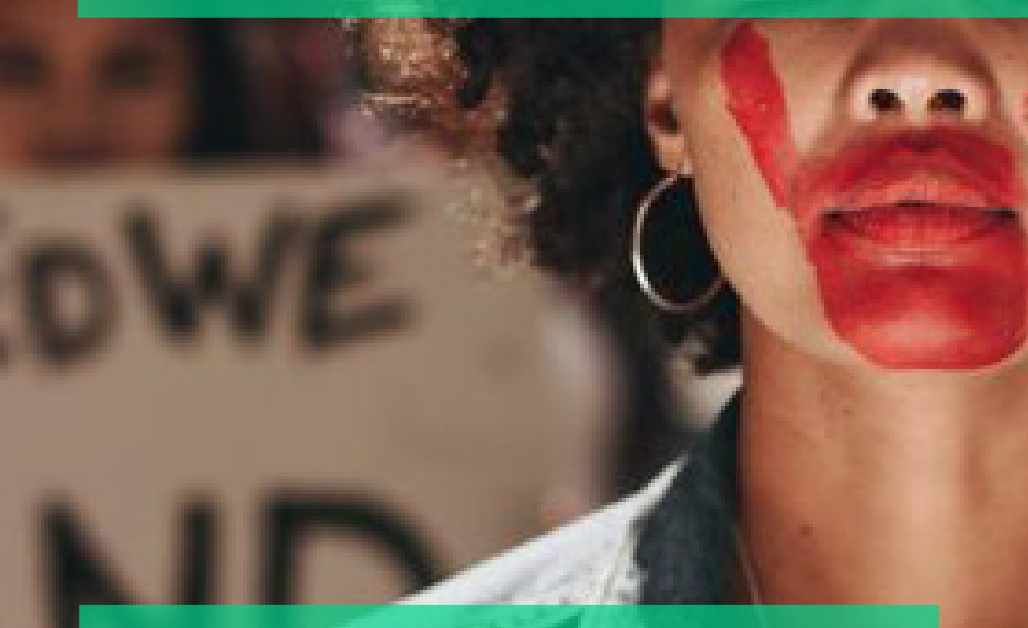

Silvana Rodrigues Mota

Psicóloga especialista em saúde mental e atenção Psicossocial, especialista em psicologia infantil mota.sibv@gmail.com

car

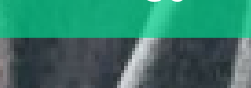

Osvaldo Piedade Pereira da Silva

Professor Mestre da Universidade Estadual de Roraima piedade23@yahoo.com.br

Foto de uma mulher em manifestação pelo fim da violência contra as mulheres. Foto: Andréa Martinelli.

\section{RESUMO}

A violência doméstica sofrida pela mulher está inserida na sociedade como um fenômeno cultural, muitas vezes, tal ato de violação ainda é silenciado por esta, que sofre este tipo de humilhação em segredo por não ter coragem ou condições de procurar o amparo da lei. Pode-se definir violência contra mulher como: qualquer ato, conduta, ou manifestação com base no gênero que cause danos, sofrimento físico, sexual ou psicológico. Tal ato muitas vezes visa à desestruturação da vítima, que na grande maioria dos casos, tem vergonha ou medo de denunciar o seu agressor. Neste sentido, este trabalho teve como objetivo analisar as consequências da violência doméstica sofrida pela mulher, e resultou-se de uma pesquisa de revisão bibliográfica, tendo como como suporte na pesquisa livros, sites e artigos científicos. Deste modo, conclui-se que a violência doméstica atinge a saúde fisica e emocional da vítima, o bem-estar de seus filhos e até a conjuntura econômica e social da vida da vítima, seja imediatamente ou à longo prazo. Dentre os quadros orgânicos resultantes, encontram-se lesões, obesidade, síndrome de dor crônica, distúrbios gastrintestinais, fibromialgia, fumo, invalidez, distúrbios ginecológicos, aborto espontâneo e morte.

Palavras chave: Violência doméstica; mulher; consequências psicoemocionais.

\section{ABSTRACT}

The domestic violence suffered by women is inserted in society as a cultural phenomenon, many times, such an act of violation still under this and muted, which suffer such humiliation in secret for not have the courage or don't find conditions to seek the protection of the law. You can set as violence against women: any act, conduct, or manifestation basis of gender that no cause damage, physical suffering, psychological sexual, etc (or). Such act many times since the disintegration of the victim, that in most cases, has shame afraid to denounce his aggressor. This, this study aimed to analyze the consequences of domestic violence suffered by the women and resulted in a research literature review, tendon as object books search, e papers sites. This follows that one domestic violence affects the physical and emotional health of the victim, the wellness of their kids and even an economic background and social life of the victim, whether or immediately to the long-term. Among the result of the organic framework, are injuries, obesity, chronic pain syndrome, gastrointestinal disorders, fibromyalgia, smoking, disability, gynecological disorders, miscarriage, and death.

Keywords: Domestic violence; women; psycho-emotional consequences.

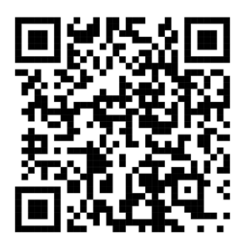




\section{INTRODUÇÃO}

A palavra violência deriva do Latim "violentia", que significa "veemência, impetuosidade", sua origem está relacionada com o termo "violação" (violare). Etimologicamente definida como todo e qualquer comportamento que cause de forma intencional danos à integridade (seja ela físico, material ou psicológica), intimidação, ou que possa invadir a autonomia, a moral e a ética de um determinado indivíduo (MACDOWELL, 2005).

Entendida e definida nesta perspectiva, o Ministério da Saúde caracteriza a violência como um fenômeno de conceituação complexa, polissêmica e controversa. Apesar disso, assume que ela é representada por ações humanas realizadas por indivíduos, grupos, classes, nações, numa dinâmica de relações, ocasionando danos fisicos, emocionais, morais e espirituais a outrem (MOREIRA, 1998).

Numa tentativa de melhor precisar suas definições sobre o fenômeno em questão, a Organização das Nações Unidas (ONU) iniciou seus esforços contra essa forma de violência, na década de 50, com a criação da Comissão de Status da Mulher que formulou entre os anos de 1949 e 1962 uma série de tratados baseados em provisões da Carta das Nações Unidas que afirma expressamente os direitos iguais entre homens e mulheres e na Declaração Universal dos Direitos Humanos - que declara que todos os direitos e liberdades humanos devem ser aplicados igualmente a homens e mulheres, sem distinção de qualquer natureza.

Diante do exposto, o presente artigo tem o propósito de abordar o tema da violência doméstica e suas consequências psicoemocionais, deste modo, o estudo que serve de base para a reflexão aqui apresentada foi realizado com o intuíto de instruir profissionais de saúde que atuam na área, colaborar com possiveis criações de políticas públicas que visem coibir estas práticas. Sua metodologia consistiu em uma pesquisa de revisão bibliográfica, que teve como base teórica conceitual categorias, conceitos e teorias encontradas em sites, artigos científicos, livros e etc.

\section{METODOLOGIA}

Este artigo configura-se como uma pesquisa descritiva de revisão literária, pois visa descrever o tema de violência doméstica e suas consequências psicoemocionais, buscando compreender tal fenômeno em sua construção sócio-histórica e patriarcal, além das consequências psicoemocionais.

A Pesquisa descritiva é uma das classificações da pesquisa científica, na qual seu objetivo é descrever as características de uma população, um fenômeno ou experiência para $\mathrm{O}$ estudo realizado. $\mathrm{Na}$ pesquisa descritiva, cabe ao pesquisador fazer o estudo, a análise, o registro e a interpretação dos fatos do mundo físico, sem a manipulação ou interferência dele. Ele deve apenas descobrir a frequência com que o fenômeno ocorre ou como se estrutura dentro de um determinado sistema, método, processo ou realidade operacional.

A pesquisa realizada caracteriza-se como exploratório-descritiva, visto que "descreve o comportamento dos fenômenos" (COLLIS; HUSSEY, 2005), estabelece relações entre as variáveis (GIL, 2002) e possibilita ao investigador maximizar seu conhecimento acerca de determinado fenômeno ou problemática (TRIVIÑOS, 1990).

Utilizou-se como ferramentas e base teórica conceitual, consulta a livros, artigos científicos, periódicos e documentos eletrônicos. Haja vista, que estes dados, foram coletados dentro do rigor científico.

\section{DISCUSSÃO}




\section{A história da violência contra a mulher}

Há séculos, as mulheres ocupam um lugar de submissão e dominação perante à sociedade, desde criança, elas recebem uma espécie de "treinamento" para cumprir a sua única função, de acordo com as regras sociais da época: tornar-se esposa e mãe. As mulheres não tinham voz na história escrita pelos homens. Vasconcelos (2005) comenta, referindo-se às mulheres, que estando elas circunscritas ao universo doméstico o limite possivel seria o mundo privado, por esse motivo não teriam uma história. Não teriam história, pois a representação que delas é feita pelos homens é insuficiente, são vistas e representadas como sobras, desprovidas de identidade ou protagonismo.

Essa forma particular de perceber e retratar as mulheres reforça e justifica comportamentos hierarquizados, que se por um lado colocam a figura masculina no centro e modelo a ser seguido, por outro lado relega à mulher a posição de subserviência e dependência cujo reflexo pode ser facilmente expresso nas formas despreziveis de violência a que são submetidas na sociedade contemporânea. É preciso lembrar, nesse particular, que a história dos comportamentos sociais se escreve a partir do passado.

Analisando a violência praticada contra a mulher no contexto doméstico, Machado e Gonçalves nos ensinam que:

Considera-se violência doméstica "qualquer ato, conduta ou omissão que sirva para infligir, reiteradamente e com intensidade, sofrimentos fisicos, sexuais, mentais ou económicos, de modo direto ou indireto (por meio de ameaças, enganos, coação ou qualquer outro meio) a qualquer pessoa que habite no mesmo agregado doméstico privado (pessoas - crianças, jovens, mulheres adultas, homens adultos ou idosos - a viver em alojamento comum) ou que, não habitando no mesmo agregado doméstico privado que o agente da violência, seja cônjuge ou companheiro marital ou ex-cônjuge ou ex-companheiro marital" (MACHADO; GONÇALVES, 2003, p. 25).
No tocante à violência praticada contra a mulher, é possivel afirmar que esta é oriunda de um longo processo de construção sóciohistórico, este, repercute nas relações de poder onde a mulher, a princípio, foi posta de lado, em um lugar de submissão, dominação; herança de uma sociedade patriarcal. Sobre essa questão, Saffioti (2004, p. 10) lembra que "o patriarcado se resume a um sistema de dominação, modelado pela ideologia machista. Mais do que isto, ele é também um sistema de exploração".

Numa definição mais geral do que realmente consiste a relação patriarcal, Weber (2004) destaca:

Patriarcado é uma forma de poder que se sustenta na autoridade de um senhor, o pai, sob seu grupo familiar. o poder do senhor é descrito como um poder arbitrário e pessoal, sendo a tradição a única possibilidade de limite a este poder. $O$ domínio patriarcal pode estender-se para além do grupo familiar, podendo alcançar extensões gigantescas, cidades e municípios, até países. Neste caso, os senhores oferecem benefícios financeiros e materiais distribuídos para não familiares em troca de devoção e obediência; realizam formação de guarda pessoal para defesa e coerção, constituição de representantes pessoais que exercem poder em seu lugar e sob obediência a suas decisões diretas. 0 estilo de governo patriarcal tem uma ideologia que caracteriza-se pelo ideal de reconhecimento e venerado como o "bom rei', 'o pai do povo' e seu protetor (WEBER, 1989, p.86).

No desejo de imprimir uma reação a essa forma histórica de imposição sobre a mulher, a partir dos anos 80, a contribuição feminina através das ideias feministas ganhou destaque no mundo acadêmico e na construção da história humana. Nesse contexto surgiram também os primeiros estudos que tratavam da violência contra a mulher, com o intuito de dar visibilidade a este tema. Neste mesmo período, para combater a violência doméstica surgem as primeiras delegacias da mulher, essas iniciativas indicam uma mudança 
importante no enfrentamento desse tipo de violência.

É interessante observar que nestes casos, o "lar" enquanto um local simbólico e real de acolhimento e proteção, perde seu sentido. Uma vez que adquire uma perspectiva ameaçadora e sombria, propiciando e facilitando a ocorrência de condutas violentas o que descaracteriza a imagem inicial que se tinha desse espaço. O lar passa ser visto, mesmo que parcialmente, como o lugar onde comportamentos e ações violentas são praticadas.

Numa relação com os processos ideológicos de poder engendrado pela figura masculina, Chauí (1985) concebe violência contra as mulheres como resultado de uma ideologia de dominação masculina. Uma vez que muitas mulheres acabam submetendo-se às vontades e aos caprichos de seus companheiros. Cabe destacar, que essa realidade indicada por Chauí (1985), se apresenta em um contexto geral em que se articulam dialeticamente os elementos da cultura e da produção da vida material reproduzida cotidianamente. A violência praticada contra a mulher, ou mesmo a violência de um modo geral, são expressões de uma totalidade que ganha traços mais nítidos com o sexismo.

$E$ é neste ambiente onde pessoas que convivem familiarmente como empregados, agregados e visitantes além de parentes e amigos promovem as diversas formas de violência intrafamiliar ou doméstica. Em algumas situações, a violência doméstica persiste cronicamente porque um dos envolvidos apresenta uma atitude de aceitação e incapacidade de se desligar daquele ambiente, seja por razões materiais, ou psicoemocionais.

De acordo com Azevedo:

As situações de violência contra a mulher resultam, principalmente, da relação hierárquica estabelecida entre os sexos, sacramentada ao longo da história pela diferença de papéis instituídos socialmente a homens e mulheres, fruto da educação diferenciada. Assim, o processo de "fabricação de machos e fêmeas", desenvolve-se por meio da escola família, igreja, amigos, vizinhança e veículos de comunicação em massa. Sendo assim, aos homens, de maneira geral, são atribuídas qualidades referentes ao espaço público, domínio e agressividade. Já às mulheres foi dada a insignia de "sexo frágil", pelo fato de serem mais expressivas (afetivas, sensiveis), traços que se contrapõem aos masculinos e,

por isso mesmo, não são tão valorizados na sociedade (AZEVEDO, 1985, p. 45).

E esse ciclo de violência doméstica se repete cada vez com mais intensidade num intervalo de tempo menor, e indefinidamente, podendo terminar em tragédias. Nesse sentido, a violência doméstica compõe um ciclo que pode se tornar vicioso, repetindo-se ao longo de meses ou anos.

Desse modo, a violência doméstica sofrida pela mulher, está inserida e constituída na sociedade como um fenômeno cultural, muitas vezes, esta prática de violação humana é silenciada pela vítima, que ainda sofre com as humilhações, seja por medo do seu agressor ou por não ter condições de procurar o amparo da lei.

De forma genérica, sabe-se que a violência é um fenômeno reconhecidamente presente na vida de muitas mulheres. Estudos realizados permitem ter uma noção sobre o quanto a violência mostra-se presente nos lares e cotidiano das famílias. Segundo o Conselho Cearense dos Direitos da Mulher (2007), aproximadamente $20 \%$ das mulheres já foram vítimas de algum tipo de violência doméstica, seja ela física, sexual ou psicológica.

Portanto, pode-se definir violência contra mulher como: qualquer ato, conduta, ou manifestação com base no gênero que cause danos, sofrimento físico, sexual ou psicológico à mulher. Tal ato muitas vezes visa à desestruturação da vítima, que na grande maioria dos casos, tem vergonha ou medo de denunciar o seu agressor (SCHRAIBER, 2002). 


\section{$(2)$}

No tocante ao gênero, cita-se Passos: É a partir deste processo sóciocultural de construção da identidade, tanto masculina, quanto feminina, que ao menino é ensinado a não maternar, não exteriorizar seus sentimentos, fraquezas e sensibilidade, a ser diferente da mãe e espelhar-se no pai, provedor, seguro $e$ justiceiro; em contrapartida, à menina acontece o oposto, ela deve identificar-se com a mãe e com as carac-

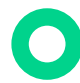

terísticas definidas com femininas: docilidade, dependência, insegurança, entre outras (PASSOS, 1999, p. 178).

Visto que, a grande maioria dos atos de violência sofridos pelas mulheres, tem por agressor seus companheiros cônjuges. Tal ato é visto por estas vítimas como algo indesejável e que causa profundo sofrimento. As mulheres acabam cedendo às investidas violentas dos companheiros por medo de denunciar, ou por vergonha em expor à sociedade o fato de ser agredida dentro de seu lar.

No entanto, tal condição não as torna cúmplices de seus companheiros agressores, pois de acordo com Saffiot (2004), as mulheres não são cúmplices das agressões de seus parceiros íntimos, pois, para tanto, precisariam desfrutar de poder igual ao que detêm os homens. Sendo detentoras de parcelas infinitamente menores de poder do que eles, apenas cedem à violência, mas não consentem. Cedem à violência por medo, mas não a aceitam.

\section{A violência contra a mulher e a lei}

Num avanço histórico, A lei 11.340 Violência Doméstica, criada em 07 de agosto de 2006, denominada de Lei Maria da Penha, em homenagem à senhora Maria da Penha Maia Fernandes ${ }^{1}$, que lutou por 20 anos para

\footnotetext{
1 Maria da Penha Fernandes Maia, Biofarmacêutica cearense foi casada com o professor universitário Antônio Herredia Viveros. Sofreu a primeira tentativa de assassinato por parte do seu companheiro em 1983, levou um tiro pelas costas enquanto dormia, deixan-
}

colocar seu agressor na prisão.

Esta lei acaba com penas alternativas ou brandas, a serem pagas com cestas básicas ou multas, e engloba todos os tipos de violência como: física, sexual, psicológica, patrimonial e moral, e tem por finalidade, garantir direitos básicos como: integridade física, psíquica, sexual, moral e patrimonial da mulher.

De acordo com o código penal, $\S 9$ do art. 129, se uma lesão for praticada contra ascendente, descendente, irmão, cônjuge ou companheiro, ou com quem conviva ou tenha convivido, de coabitação ou de hospitalidade: a pena - detenção, de 3 (três) meses à 3 (três) anos.

O Art $1^{\circ}$ - Esta lei cria mecanismos para coibir e prevenir a violência doméstica e familiar contra a mulher, nos termos do§ $8^{\circ}$ do art. 226 da constituição federal, da convenção sobre a eliminação de todas as formas de violência contra a mulher, da convenção interamericana para prevenir, punir e erradicar a violência contra a mulher e de outros tratados internacionais ratificados pela República Federativa do Brasil; dispõe sobre a criação dos juizados de violência doméstica e familiar contra a mulher; estabelece medidas de assistência e proteção às mulheres em situação de violência doméstica e familiar (BRASIL ,2008).

Assim, a mulher pode sofrer violência em todas as fases de sua vida, ocorrer em todas as classes sociais, algumas vezes iniciando-se ainda no período da infância e perdura por longo período ou por toda a vida da vítima. Segundo o artigo 70 da lei no 11.340/2006 Violência doméstica, são formas de violência contra a mulher:

I - Violência física, entendida como qualquer conduta que ofenda sua integridade ou saúde corporal.

II - A violência psicológica, entendida como qualquer conduta que lhe cause dano emocional $e$ diminuição da autoestima ou que lhe prejudique e perturbe o pleno desenvolvimento ou que

do-a paraplégica. Meses depois Antônio a empurrou da cadeira de rodas e tentou eletrocutá-la no chuveiro. 
vise degradar ou controlar suas ações, comportamentos, crenças e decisões, mediante ameaça, constrangimento, humilhação, manipulação, isolamento, vigilância constante, perseguição contumaz, insulto, chantagem, ridicularização, exploração e limitação do direito de ir e vir ou qualquer outro meio que lhe cause prejuizo à saúde psicológica e à autodeterminação.

III - A violência sexual, entendida como qualquer conduta que a constranja a presenciar, a manter ou a participar de relação sexual não desejada, mediante intimidação, ameaça, coação ou uso da força; que a induza a comercializar ou a utilizar, de qualquer modo, a sua sexualidade, que a impeça de usar qualquer método, de qualquer modo contraceptivo ou que a force ao patrimônio, à gravidez, ao aborto ou à prostituição, mediante coação, chantagem, suborno ou manipulação; ou que limite ou anule o exercício de seus direitos sexuais e reprodutivos.

IV - A violência patrimonial, entendida como qualquer conduta que configure retenção, subtração, destruição parcial ou total de seus objetivos, instrumentos de trabalho, documentos pessoais, bens, valores e direitos ou recursos econômicos, incluindo os destinados a satisfazer suas necessidades.

$V$ - A violência moral, entendida como qualquer conduta que configure calúnia, difamação ou injúria (BRASIL. 2006).

Na prática, essa lei busca proteger mulheres em situação de vulnerabilidade, que estejam em situação de violência, através de medidas protetivas, e até mesmo com a privação de liberdade do agressor (prisão).

\section{Consequências psicológicas da violência doméstica}

A Organização Mundial de Saúde (OMS) reconhece a violência doméstica contra a mulher como uma questão de saúde pública, que afeta negativamente a integridade física e emocional da vítima, seu senso de segurança, configurada por círculo vicioso de "idas e vindas" aos serviços de saúde e o consequente aumento com os gastos neste âmbito (GROSSI, 1996).

De acordo com Dias (2006), o Relatório Nacional Brasileiro retrata o perfil da mulher brasileira e mostra que: a cada 15 segundos uma mulher é agredida, totalizando, em 24 horas, um número de 5.760 mulheres espancadas no Brasil. Já os dados da Organização Mundial da Saúde (OMS), em 2005, mostram que, no Brasil, $29 \%$ das mulheres sofreram violência física ou sexual ao menos uma vez na vida; $22 \%$ não conseguiram falar para ninguém sobre o ocorrido; e $60 \%$ não saíram mais de suas casas, nem sequer por uma noite. A violência doméstica quando ocorre independe do status social, escolaridade ou raça (SOARES, 2004).

Assim, estes dados mostram que que apesar de estarmos em pleno século XXI, os números continuam a crescer a cada dia, independente da classe social, raça, cor e etc, muitas mulheres sofrem violência, seja ela de cunho físico, emocional ou sexual.

A violência contra as mulheres é o tipo mais frequente de abuso de direitos humanos mais frequentes e talvez o menos reconhecido. Deste modo, a assembléia Geral da Organização Pan-Americana de Saúde, de 1991, definiu oficialmente a violência sofrida pelas mulheres como: "Qualquer ato de violência de gênero que resulte ou possa resultar em dano físico, sexual, psicológico ou sofrimento para a mulher, inclusive ameaças de tais atos, coerção ou privação arbitrária da liberdade, quer ocorra em público ou na vida privada".

Como um problema multidisciplinar genuíno e genérico, requer a estreita cooperação de uma ampla gama de diferentes profissionais com diferentes tarefas. Como um problema legal e terapêutico, requer, por parte de todos os profissionais envolvidos, o conhecimento dos aspectos criminais em de proteção da criança, assim como dos aspectos psicológicos (FURNISS, 1993).

A violência doméstica deixa marcas profundas e muitas vezes inesqueciveis. A mulher que sofre vários tipos de violência ao mesmo tempo, acaba por adquirir sintomas e até mesmo doenças de cunho físico e psicológico, devido às agressões. 


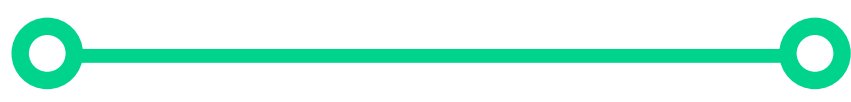

Deste modo:

Os sintomas psicológicos frequentemente encontrados em vítimas de violência doméstica são: insônia, pesadelos, falta de concentração, irritabilidade, falta de apetite, e até o aparecimento de sérios problemas mentais como a depressão, ansiedade, sindrome do pânico,

estresse pós-traumático, além de comportamentos autodestrutivos, como o uso de álcool e drogas, ou mesmo tentativas de suicidio (KASHANI; ALLAN, 1998, p. 15).

Assim, paratentar suportar essa realidade a mulher precisa abdicar não somente de seus sentimentos, mas também de sua vontade. Com isso, ela passa a desenvolver uma auto percepção de incapacidade, inutilidade e baixa autoestima pela perda da valorização de si mesma e do amor próprio (MILLER, 1999).

Em face de tal realidade, desenvolvemse concepções populares de que as mulheres "gostam de apanhar", ou ainda de que "algo fizeram para merecerem isto". Esta ideia nega a complexidade do problema e atribui à violência um caráter individual, oriundo de aspectos específicos da personalidade feminina (GROSSI, 1996).

Oliveira (2009) apud Reis, Carolina da Rosa (2013, p.3) refere que "as mulheres vítimas de violência têm queixas, distúrbios e patologias, físicas e mentais, e utilizam os serviços de saúde com maior frequência do que aquelas sem esta experiência".

As consequências psicoemocionais da violência doméstica atingem o bem-estar e até a vida social da vítima, seja imediatamente ou à longo prazo. Segundo Day (2003), esses danos psicológicos podem ser imediatos ou tardios, no primeiro refere-se a pesadelos repetitivos, raiva, culpa, ansiedade, medo do agressor e de pessoas do mesmo sexo, quadros fóbico-ansiosos e depressivos agudos, queixas psicossomáticas, isolamento social e estigmatização.
Para se entender as marcas psicoemocionais de um indivíduo vítima de violência doméstica, é necessário um olhar mais profundo, que busque os seus sentimentos que foram atingidos pelo ato da violência, seja ela física ou psicológica.

\section{Reflexão da discussão}

Atualmente, sabe-se que a violência doméstica é um fenômeno reconhecidamente presente na vida de muitas mulheres. Estudos realizados possibilitam ter uma noção sobre o quanto a violência mostra-se presente nos lares e cotidiano das famílias.

Segundo Dias (2006) váriossão os motivos pelos quais a primeira agressão sofrida geralmente, não é denunciada: a mulher pode vivenciar um conflito, por não desejar separar-se do companheiro ou, mesmo que ele seja preso, apenas pretende que cessem as agressões, procurando socorro, somente quando já está cansada de apanhar e se sente impotente.

De acordo com a Declaração das Nações Unidas, de 1949, sobre a Violência Contra a Mulher, aprovada pela Conferência de Viena em 1993 a violência se constitui em "[...] todo e qualquer ato embasado em uma situação de gênero,na vida pública ou privada, que tenha como resultado dano de natureza física, sexual ou psicológica, incluindo ameaças, coerção ou a privação arbitrária da liberdade" (ADEODATO, 2006, p.2).

Segundo Miller (1999), por mais que a sociedade estabeleça estereótipos para o homem agressivo - como rude, de classe social inferior, grosseiro, valentão na aparência e nas atitudes - não há um perfil único. Assim, um homem que em sociedade pode parecer acima de qualquer suspeita, pode, muito bem, ser um agressor na relação conjugal.

$\mathrm{O}$ ato de violência, seja qual for a forma, gera na vítima, segundo Kashani e Allan (1998), prejuízos nas esferas do desenvolvimento físico, cognitivo, social, moral, emocional ou 
afetivo. As manifestações físicas da violência podem ser agudas, como as inflamações, contusões, hematomas, ou crônicas, deixando sequelas para toda a vida, como as limitações no movimento, traumatismos, a instalação de deficiências fisicas, entre outras.

Deste modo, as consequências psicológicas podem ter resultado das agressões como também podem aparecer de forma isolada na vítima. Para tanto Fonseca (2012) nos traz um rol exemplificativo de algumas enfermidades psicológicas, dentre as quais são elencadas o estresse póstraumático, depressão, ansiedade, fobias.

Portanto, foi possivel verificar através dos estudos realizados que a violência doméstica trás consequências graves para a vida da vítima, a curto e longo prazo. Tais consequências afetam não somente a mulher agredida, como também o seu lar, e no que tange as consequências psicoemocionais, se ão receberem o amparo adequado, poderão voluir para quadros patológicos mais graves.

\section{CONSIDERAÇÕES FINAIS}

A violência doméstica sofrida pela mulher constitui um grave problema de saúde pública, que merece a atenção da sociedade e dos órgãos governamentais,neste sentido, faz-se necessário criar políticas públicas para coibir e prevenir este tipo de violência, e fortalecer o sistema de apoio à vítima e implementação de amplo processo de educação que faça frente à naturalização do inaceitável.

Este fenômeno é compreendido como uma questão de direitos humanos, uma vez que visa inferiorizar, subjugar, e afrontar a dignidade da mulher como ser humano, além de impedir/interromper o desenvolvimento da mulher como ser social, privando-a de sua dignidade e liberdade de vontade e de escolha.

A violência doméstica gera consequências à saúde física e psicológica da mulher, o impacto da violência afeta também a percepção da mulher sobre si mesma, através dos sentimentos de insegurança, impotência, medo e até suas relações com o meio social.

Quando se trata de violência doméstica, é cabível esclarecer, que o tratamento diferenciado previsto na Lei Maria da Penha ofertado à mulher não se remete à generalidade de sua vitimização, mas sim, à necessidade de oferecer suporte e proteção a vítima, visto que esta sofre um processo de vulnerabilidade histórica, ou seja, necessita de proteção especial por parte da lei e do Estado.

Neste sentido, este trabalho teve relevância social e acadêmica, uma vez que pode servir de subsídio para auxiliar na criação de políticas públicas. Visto que, necessitase entender toda essa problemática, para auxiliar no amparo às vítimas, dando-lhes o tratamento adequado e na criação de leis ainda mais rígidas para coibir este tipo de violência.

Portanto, este artigo pode proporcionar conhecimentos para a formação dos futuros psicólogos, profissionais da área da saúde e segurança pública que atuem diretamente com esta temática, ou que desejarem atuar nas áreas de enfrentamento da violência contra a mulher, uma vez que pode possibilitar sensibilização para a criação de redes de poio à mulher vítima da violência doméstica.

\section{REFERÊNCIAS}

ADEODATO, Vanessa Gurgel et al. Qualidade de vida e depressão em mulheres vítimas de seus parceiros. Revista de Saúde Pública, v. 39, n. 1, fev. 2006 (online). Disponível em: Acesso em novembro de 2016.

AZEVEDO, M. A.; Violência física contra a mulher: dimensão possível da condição feminina, braço forte do machismo, face oculta da família patriarcal ou efeito perverso 
da educação diferenciada? In:. Mulheres espancadas: a violência denunciada. São Paulo: Cortez, 1985.

Conselho Cearense dos Direitos da Mulher CCDM. (2007). Estatísticas de ocorrências da Delegacia de defesa da mulher, Fortaleza. (links). Acesso em novembro de 2013.

CHAUİ, M.; "Participando do Debate sobre Mulher e Violência". In: Franchetto, Bruna, Cavalcanti, Maria Laura V. C. e Heilborn, Maria Luiza (org.). Perspectivas Antropológicasda Mulher 4, São Paulo, Zahar Editores, 1985.

COLLIS, J.; HUSSEY, R. Pesquisa em Administração: um guia prático para alunos de graduação e pós-graduação. 2. ed. Porto Alegre: Bookman, 2005.

DAY, V. P.; TELLES, Elaine de Borba; et all. Violência doméstica $e$ suas diferentes manifestações: Revista de psiquiatria, RS. Abril de 2003.

DIAS, M. B.; A impunidade dos delitos domésticos. Palestra proferida no IX Congresso Nacional da Associação Brasileira das Mulheres de Carreira Jurídica. Alagoas. Disponivel em: <www.mariaberenice.com.br>. Acesso em maio de 2015.

FONSECA, Denire Holanda da; RIBEIRO, Cristiane Galvão; LEAL, Noêmia Soares Barbosa. Violência doméstica contra a mulher: realidades e representações sociais. João Pessoa, 2012. Disponível em: <http://www. scielo.br/pdf/psoc/v24n2/07.pdf>. Acesso em dezembro de 2017.

FURNISS T. 0 abuso sexual da criança. Tradução Mara Adriana Veríssimo Veronese. Porto Alegre: Artes Médicas, 1993.

GIL, A. C. Como elaborar projetos de pesquisa. 4. ed. São Paulo: Atlas, 2002.
GROSSI, K. Violência contra a mulher: Implicações para os profissionais de saúde. In: LOPES, M. J. M.; MEYER, D. E.; WALDOW, V. R. (Orgs.) Gênero e Saúde. Porto Alegre: Artes Médicas, 1996. P. 133-149.

Lei $\mathrm{n}^{\circ}$ 11.340, 7 de agosto de 2006. (2008) Diário Oficial da União. Brasília, DF: Imprensa Nacional. Ano CXLIII, n. 151, Seção 1. (links).

KASHANI, J. H,; ALLAN, W. D.; The impact of family violence on children and adolescents. Thousand Oaks, Ca: Sage,1998. P. 15.

MACHADO, C. E GONÇALVES, R. A. (2003), Violência e Vítimas de Crimes.Coimbra: Quarteto.

MACDOWELL, C. S.; Violência contra as Mulheres e Violência de Gênero. Universidade de São Paulo. São Paulo, 2005.

MERGÁR, Ar.; A representação social do gênero feminino nos autos criminais na Província do Espírito Santo (1853-1870).2006. $160 \mathrm{f}$. Dissertação (Mestrado) - Programa de PósGraduação em História Social das Relações Políticas, Universidade Federal do Espírito Santo, Centro de Ciências Humanas e Naturais, Vitória, 2006.

MILLER, Mary Susan. Feridas invisiveis: abuso não-físico contra mulheres. TraduçãoDenise Maria Bolanho. São Paulo: Summus, 1999.

MOREIRA, V. (1998). Grupo de Encontro com mulheres vitimas de violência familiar. Estudos de psicologia, 4 (4), 61-78. (links).

OLIVEIRA, E. M. et al. (2005). Atendimento às mulheres vitimas de violência sexual: um estudo qualitativo. Saúde Pública,39(3), 376382. Apud Reis, Carolina da Rosa (2013, p.3).

Organização Pan-americana da Saúde. Relatório sobre a saúde no mundo 2001: Saúde Mental: nova concepção, nova esperança. 
Brasil; 2001.

WEBER, M.; Conceitos Básicos de Sociologia.

São Paulo: Moraes, 1989.

PASSOS, E. S.; Palcos e platéias: as representações de gênero na Faculdade de Filosofia. Salvador: UFBA; Núcleo de Estudos Interdisciplinares sobre a Mulher, 1999.

SAFFIOTI, H. J. B. (2004). Gênero, patriarcado, violência. São Paulo: Fundação Perseu. Abramo. P, 10. 